\title{
Monocytic Croup; Probably the First Case ever Published.*
}

By
Alkira Sato, Kazuo Tachibana and Jun-ichi Ishikawa.
（佐 藤 彰） (立花一未) (石川澋一)

(From Department of Pediatrics, Faculty of Medicine, Tohoku

University, Sendai. Director: Prof. A. S a to.)

(Received for publication, April 16, 1949)

Cases of monocytic angina are too numerous to enumerate, while there is no case reported of " monocytic croup," so that we are rather surprised at the penetrative and instructive description by Wintrobe') to the effect that laryngeal obstruction is unknown.

\section{Case Report.}

A. H., a girl aged 22 months, was admitted to our Pedlatric Clinic on Oct. 31, 1945 with complaints of high fever, stridor and aphonia. On the presumptive diagnosis: "Diphtheric Croup" 3,000 units of antitoxin were injected intramuscularly, even though diph theria bacilli had not been identified. The next day 4,000 units were given again. Laryngoscopic examination on Nov. 2 showed a reddened and edematous larynx without any membrane; no diphtheria bacilli on culture. Temperature was nearly $40^{\circ} \mathrm{C}$ on Nov, $1,38^{\circ} \mathrm{C}$ on the next day; then it was irregular, though mostly not feverish. The girl, almost recovered, was discharged after 2 weeks' stay.

Blood will be shown by way of ELMoNogram (Fig. 1 and Fig. 2) ${ }^{2}$; monocyte count was ca. 9400 (white count was 12,000) on Nov. 2.

Fig. 1 .

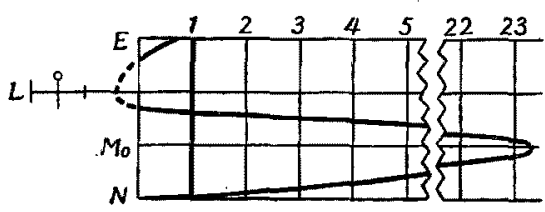

Elmonogram of our case
Fig. 2.

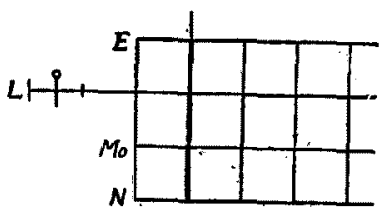

Elmonogram for 2 years of age

As shown by Longscope ${ }^{3)}$ in cases of infectious mononucleosis, a certain relation between temperature curve and absolute count of mononuclear cells was observed in our case. As to details of the course, the blood picture and the hemo-myelogram cf. 86th Hematological Paper.4)

"Monocytic Croup" was suggested by us for the disease.

\section{Literature.}

1) M. M. Wintrobe, Clinical Hematology, 2nd Edit., Philadelphia, 1947, 803.

2) A. Sato and K. Hayashi, Tohoku J. Exp. Med., 1947, 49, 37.

3) W. T. Longscope, Amer. J. Med. Science, 1922, 164, 781.

4) K. Tachibana and I. Ishikawa, 84th Hematological Paper, Tohoku J. Exp. Med. to be published in a forthcoming number of this Journal.

* Read at the 32nd General Meeting of the Tohoku Medical Society, Senidai, Nov. 2, 1947. 